\title{
Performance-Based Design through Implementation of FEMA P-58 Methodology in Developing Countries
}

\author{
Amir Masoumi Verki¹, Seyed Bahram Beheshti Aval2 \\ ${ }^{1}$ Graduated Student in Master Degree of Earthquake Engineering, K. N. Toosi University of Technology, Tehran, Iran \\ ${ }^{2}$ Faculty of Civil and Environmental Engineering, K. N. Toosi University of Technology, Tehran, Iran \\ Email: a.masoumi.v@gmail.com
}

How to cite this paper: Verki, A.M. and Aval, S.B.B. (2020) Performance-Based Design through Implementation of FEMA P-58 Methodology in Developing Countries. Open Journal of Earthquake Research, 9, 255-272. https://doi.org/10.4236/ojer.2020.93015

Received: January 19, 2020

Accepted: April 10, 2020

Published: April 13, 2020

Copyright () 2020 by author(s) and Scientific Research Publishing Inc. This work is licensed under the Creative Commons Attribution International License (CC BY 4.0).

http://creativecommons.org/licenses/by/4.0/ (c) (i) Open Access

\begin{abstract}
This paper investigates a simple approach proposed towards performancebased earthquake engineering (PBEE) which has potential applications to the performance-based design (PBD) and performance-based assessment (PBA) fields. The simple method of PBEE encompasses three areas of seismic risk which include seismic hazard, structural analysis, and loss models. The aim of the PBEE process, entitled as FEMA P-58, is to present essential data needed to make a rational decision regarding predicted performance, where various sources of uncertainties are involved. In developing countries, the lack of suitable real ground motions corresponding to site characteristics and seismicity particularly for larger intensities and the scarcity of demands, which makes it hard to identify the seismic capacity of a structure, is the main our motivation of using the FEMA method. In this paper, the method of FEMA P-58 is investigated, in terms of available tools and required data, in such a way that it will be applicable for developing countries which are located in high seismic hazard zones. To achieve this goal, three steel moment-resisting buildings with low and high ductility, and three steel braced-frame buildings are selected as case studies. The mean annual loss is estimated by the available software, Performance Assessment Calculation Tool (PACT). The achieved results, i.e. the loss curves, will provide a simple means by which the engineers can quantify and communicate seismic performance to other stakeholders. In the case study buildings, the braced one has less annual losses in comparison with other investigated cases, and the structure with high ductility can be considered as the next ones. Execution cost of each building should be considered by contractors. Also, seismic fragility curves of structures for various limit states, as well, the corresponding loss models are identified as the most essential data towards application of the investigated
\end{abstract}


PBEE process.

\section{Keywords}

Performance-Based Earthquake Engineering (PBEE), Performance-Based Design (PBD), FEMA P-58, Performance-Based Assessment (PBA), Decision Making Analysis, Steel Buildings, Loss Estimation

\section{Introduction}

Seismic performance assessment of structures is a process in which performance indicators, namely decision variables (i.e. financial losses, downtime and human casualties) are specified and compared with predefined performance objectives. The promising procedure, namely FEMA-58 method [1], aims to predict the decision variables where various sources of uncertainties are involved through a consistent probabilistic manner. Towards being thoroughly applicable for developing countries, the required data, existing tools and challenges to achieve the final results must be investigated.

According to the force-based seismic design regulations, the earthquake shocks have been modeled as induced inertia forces to the structures [2]. Conversely, the permission of occurrence of structural damages against severe earthquakes, with low probability of exceedance and high consequences, motivates researches to replace seismic-induced displacement with that of inertia force as the design parameter. Performance-based earthquake engineering aims to insure the desired overall structural performance through restricting the seismic-induced forces (for the brittle structural members) and the seismic-induced displacements (for the ductile structural members) against various earthquake hazard levels. Several standards have been developed according to the performance-based earthquake engineering philosophy (namely, CEN-2005 [3], JGS4001-2004 [4], AS/NZS-1170-2002 [5] and ...). A large amount of seismic-induced economic losses during recent earthquakes revealed limitations of the first generation performance-based regulations [6]. These challenges consist of the structural performance expression using non-comprehensible variables for all stakeholders and the large amount of inherent uncertainties in the predicted performance which have not been involved explicitly in the design process. According to the mentioned shortcomings, the next generation performance-based earthquake engineering guideline was presented. The promising procedure, namely the FEMA P-58, aims to express the structural performance using the comprehensible variables (i.e. seismic-induced economic losses, number of casualties and downtime) for all contributed stakeholders. Furthermore, the inherent uncertainties are involved explicitly. Through the FEMA P-58 procedure, the uncertainties of performance indicators (i.e. Decision Variables) are comprised of strong ground motion Intensity Measure (IM) uncertainty, structural seismic response (Engineering Demand Parameter: (EDP)) uncertainty, and seismic-induced damages 
(DM). Uncertainty of strong ground motion intensity measure is presented by probabilistic seismic hazard analysis. Probabilistic Seismic Hazard Analysis (PSHA) shows the Mean Annual Frequency of exceedance (MAFE) for the selected IM. Uncertainty of EDP is characterized through Incremental Dynamic Analysis (IDA) procedure, through which the structure is excited by several strong ground motions. Uncertainty of seismic-induced damage is presented by the fragility curves. Fragility curves corresponding to the local and global limit states present the probability of the relevant damage conditioned on the affected EDP [7]. Uncertainty of Decision Variable (DV) (consists of economic losses, number of casualties and downtime) is characterized by loss functions. For each considered damage states, the relevant loss functions show the probability of DV conditioned on the activated damage [8]. Mathematical formulation for estimating the mean annual frequency of decision variables (DV) is presented in Equation (1) which is formulated according to the conditional probability theorem through which the contributed uncertainties due to IM, EDP, DM and DV are involved. The integrations are implemented over Damage Measure (DM); engineering demand parameter (EDP), and intensity of ground motion (IM) variables. In Equation (1) the function $G(X \mid Y)$ shows the cumulative distribution function of $X$ conditioned on $Y$. Equation (1) is used to calculate the mean annual frequency of occurrence.

$$
\begin{aligned}
& \lambda[D V] \\
& =\iiint G(D V \mid D M) \mathrm{d} G(D M \mid E D P) \mathrm{d} G(E D P \mid I M) \mathrm{d} \lambda(I M) \mathrm{d}(E D P) \mathrm{d}(D M)
\end{aligned}
$$

The FEMA-P 58 seismic performance-based methodology is a 10-year-program which aims to develop the seismic design guidelines which will be applicable for new and existing buildings. Furthermore, the methodology is in consistent with the explosion engineering, the fire engineering and the wind engineering regulations. The project is still under development by FEMA team [9]. The seismic performance assessment will be implemented through the intensity-based, the scenario-based and the time-based procedures. The proposed decision variables are repair cost, number of casualties and downtime [1].

Available tool: Performance Assessment Calculation Tool (PACT software) is one of the tools developed based on FEMA-P 58 formulation. Besides, the necessary supporting data (such as fragility curves and relevant loss functions) to calculate the seismic performance of the buildings are presented in PACT. To use the package, the building general information(such as number of stories, total replacement cost, floor area, story height, building occupancy, etc.), population model (i.e. number of inhabitants), component fragility functions of the building, performance groups hazard curves of the located zone and structural analysis results (i.e. structural seismic response values) are the inputs to the package. The loss curves (which show the probability of loss values) are the output [1]. In this software, it is possible to make the appropriate modifications to the input variables according to the existing features to achieve more accurate results. First of all, performance parameters should be specified. Then, the col- 
lapse fragility curve should be specified. This curve is calculated based on Incremental Dynamic Analysis, through which the structure is excited by number of strong ground motions with increasing intensities. The collapse points are characterized as the intensity for which the numerical model will not converge applying any of the existing algorithms. The probability distribution fitted to the collapse points presents the collapse fragility curve. As the next step, the structural analysis results are required. Through this step, vectors of structural demands (such as inter-story drift ratio, floor acceleration, floor velocity, etc.) should be specified against number of strong ground motions scaled to the various intensities. Based on the input demand vectors, the corresponding probabilistic model is generated and hundreds of realizations are produced applying the Monte Carlo simulation method. Using the previously-defined fragility curves of the damage states, the simulated demand vectors present the damage probabilities. Finally, the loss values and the relevant exceedance probabilities are summed up for all damage states [8] [10]. Applying the collapse fragility curve and the exceedance probability of loss, the final loss value, condition on the affected IM, is estimated based on Equation (2). This equation is used to calculate the total annual losses for both collapsed and non-collapsed conditions using the general probabilistic-statistical laws.

$$
\begin{aligned}
& \begin{aligned}
G(\text { \$loss } \geq L \mid I M)= & G(\text { \$RepairCost } \geq L \mid I M \& N C) \times P(N C \mid I M) \\
& +G(\$ \text { loss } \geq L \mid C O) \times P(C O \mid I M)
\end{aligned} \\
& \text { where }: P(N C \mid \text { im })=1-P(C P \mid I M)
\end{aligned}
$$

In Equation (2), $G(\$ l o s s \geq L \mid I M)$, represents total loss of the structure (including repair cost, downtime, casualties). The $\mathrm{CO}$ and NC stands for collapse and non-collapse states. Therefore, $G($ RepairCost $\geq L \mid I M \& N C)$ shows the exceedance probability of loss conditioned the affected IM assuming the collapse doesn't occur. The calculation of this probability is explained in the previous paragraph. $P(N C \mid I M)$ is the probability of NC conditioned on IM, which is one minus the collapse fragility curve. $G(\$ l o s s \geq L \mid C O)$ is the exceedance probability of loss while the structure collapses. This function can be assumed as the probability of building replacement cost. Finally, $P(C O \mid I M)$ is the collapse fragility curve. To obtain the mean annual frequency of exceedance (MAFE) of loss, the calculated loss curve (based on Equation (2)) is integrated over the probabilistic seismic hazard curve, which shows the MAFE for the selected IM (normally $S_{a}\left(T_{1}\right)$ ). Towards making the performance assessment calculation tool (PACT) applicable for developing countries, the required input data and the relevant challenges should be investigated.

In the present study, the performance assessment calculation tool (PACT) is applied to study the seismic performance of sampled structures. The sampled structures are representatives of typical structures in developing countries. $\mathrm{Di}$ agonal braces, ordinary moment-resisting frame and special moment-resisting frame are selected as typical structures in developing countries. In developing 
countries, we face to lack lots of information about Seismic design methodology and loss models and seismic hazard. So, in this paper, we try to implement FEMA methodology for these countries. Because of high seismic potential of these countries, the FEMA has been selected. Seismic performances of structures are calculated based on FEMA P-58 methodology and by PACT tool. As the inputs of PACT tool, probabilistic seismic hazard model is presented based on power function whose constants are calibrated based on empirical seismic hazard data. Probabilistic seismic demand model is calculated based on Incremental Dynamic Analysis of the sampled frames against number of earthquake strong ground motions. Fragility functions corresponding to two commonly used limit states (i.e. Immediate Occupancy and Collapse Prevention) are estimated using the IM-based method based on IDA results. Calculated seismic loss curves will present the powerful tool to compare the seismic performance of the sampled structures and to make rational decisions if the reliable prerequisite input data are provided.

\section{Modeling and Assumptions}

To represent the results of analytical studies, three random structural frames were selected from three separated steel buildings (a braced frame and two special moment resisting frames with high and low ductility. The frames were loaded based on UBC97 code [11] and designed based on AISC 360 [12] as depicted in Table 1. To validate results, a two-dimensional (2D) model was created as shown in Figure 1. Then, one of the side frames was analyzed as the representative of the buildings to take into account some design parameters, such as biaxial bending for designing of the columns [13]. In this paper, in order to

Table 1. Used sections for braced and special moment frames (with different ductility).

\begin{tabular}{|c|c|c|c|c|c|}
\hline \multicolumn{6}{|c|}{ Braced Frame } \\
\hline \multicolumn{2}{|c|}{ Beams Sections } & \multicolumn{2}{|c|}{ Columns Sections } & \multicolumn{2}{|c|}{ Brace Sections } \\
\hline B1 & IPE300 & $\mathrm{C} 1$ & $\mathrm{BOX} 180 * 16$ & $\mathrm{Br} 1$ & $2 \mathrm{UNP} 100 * 10$ \\
\hline B2 & IPE270 & $\mathrm{C} 2$ & $\mathrm{BOX} 180 * 10$ & $\mathrm{Br} 2$ & $2 \mathrm{UNP} 90 * 10$ \\
\hline \multirow[t]{2}{*}{ B3 } & IPE240 & $\mathrm{C} 3$ & $\mathrm{BOX} 160 * 10$ & $\mathrm{Br} 3$ & $2 \mathrm{UNP} 80 * 8$ \\
\hline & & $\mathrm{C} 4$ & $\mathrm{BOX} 140 * 10$ & $\mathrm{Br} 4$ & $2 \mathrm{UNP} 70 * 8$ \\
\hline \multicolumn{6}{|c|}{ Special Moment Frames } \\
\hline \multicolumn{4}{|c|}{ Beams Sections } & \multicolumn{2}{|c|}{ Columns Sections } \\
\hline B1 & \multicolumn{3}{|c|}{ IPE330 } & $\mathrm{C} 1$ & $\mathrm{BOX} 200 * 16$ \\
\hline B2 & \multicolumn{3}{|c|}{ IPE300 } & $\mathrm{C} 2$ & $\mathrm{BOX} 180 * 16$ \\
\hline B3 & \multicolumn{3}{|c|}{ IPE270 } & $\mathrm{C} 3$ & $\mathrm{BOX} 180 * 10$ \\
\hline B4 & \multicolumn{3}{|c|}{ IPE240 } & & \\
\hline B5 & \multicolumn{3}{|c|}{ IPE220 } & & \\
\hline B6 & \multicolumn{3}{|c|}{ IPE200 } & & \\
\hline
\end{tabular}




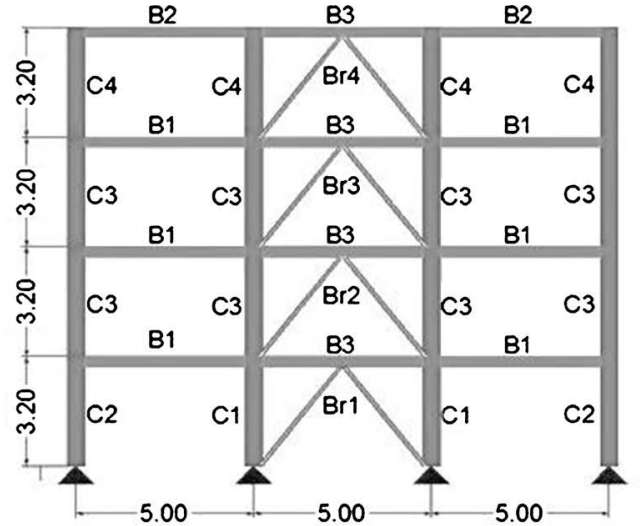

(a)

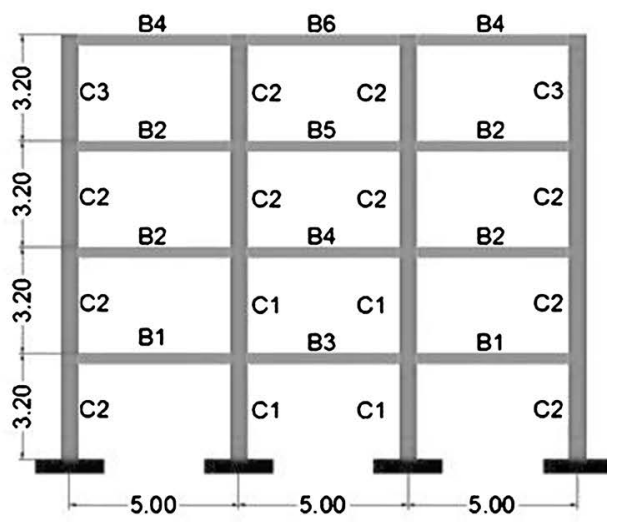

(b)

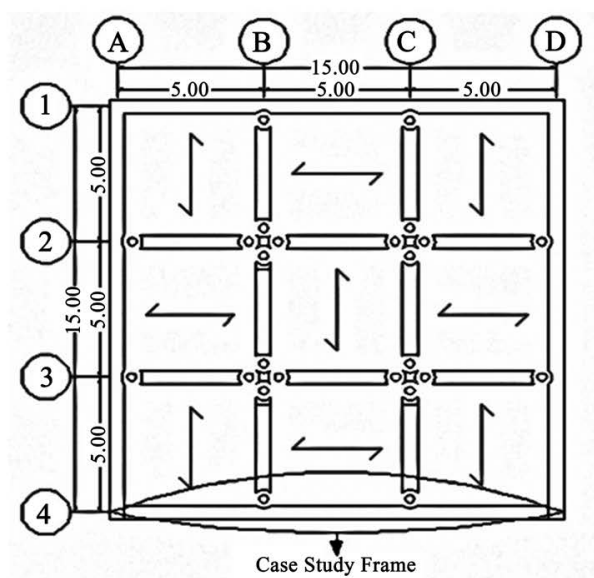

(c)

Figure 1. Two dimensional models: (a) braced frame (b) special moment frame (with different ductility) (c) plan view of case study buildings caption).

achieve different ductility, two types of connections were used in existing buildings in Northridge (named as Pre-Northridge and Post-Northridge Connections) to achieve two different ductilities of frames [6]. Common frame connections before Northridge earthquake were mostly welded joints of WUF, but majority of designers preferred to use RBS connections and bolted connections after the earthquake for residential and/or office buildings with medium hazard level [14].

It should be mentioned that columns with box sections in the moment frames are selected to achieve easier modeling [15]. Moreover, the value of behavior factor for the structure with special moment-resisting frame (SMRF) is equal to 8.5 and 7.5 for buildings with dual system and with special moment frame System. It is worth noting, according to the UBC97 code, buildings with usual moment frame system are not suggested for located in high risk zones. So, three different types of connections were used in modeling of above buildings to achieve different ductility. The first type is center to center non-linear connections used in dual braced frame modeling. Since structural stiffness and strength are two major criteria used to design new buildings and/or used to assess existing buildings. It is recommended that center to center non-linear modeling be 
used for dual braced frames. Second type of connection, used in the frames with high and low ductility, is non-linear model with spring connection in which beam and column dimensions are regarded as connection spring dimensions. In this type of modeling, a three-linear torsional spring and two double-linear torsional springs can be used in one of the connecting corners to assign a three-linear behavior [16].

Regarding to convergent bracing frames (CBFs) have numerous applications in buildings as lateral load systems, seismic performance of these bracings depends on their hysteresis cycle. In connection modeling, fiber model was used for braced connections' modeling and center to center non-linear connections were used for modeling of braced frames modeling.

To model low and high ductilities connections in Open Sees software, plastic hinge length was used as the criteria to make rigid and semi-rigid connections of such buildings (Figure 2). Support columns were used to take into account the effect of gravitational load on interior moment frames and applied demands on exterior moment frames [15]. These columns are, in fact, main rigid members which are connected to the main structure by rigid beams in both sides of the

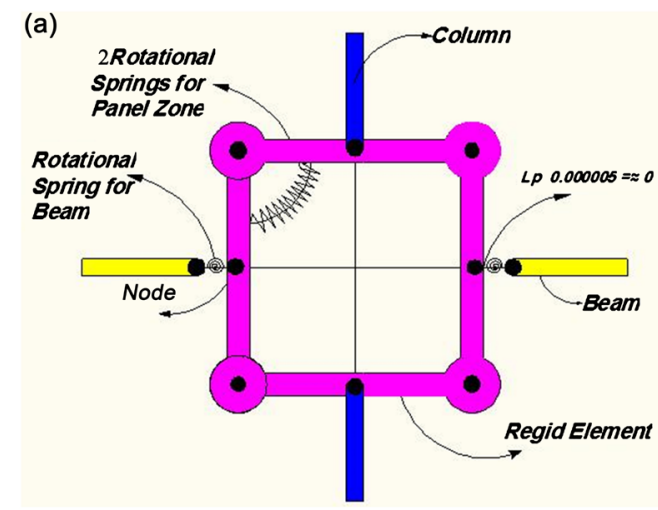

(c)

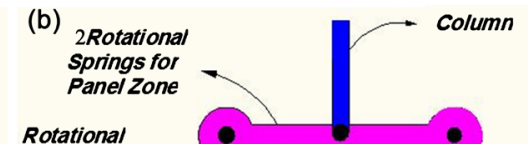

Spring for Spring for Beam
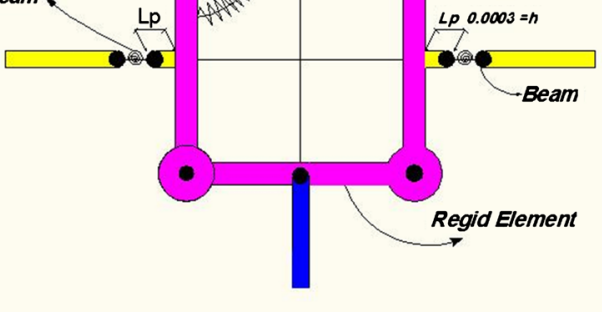

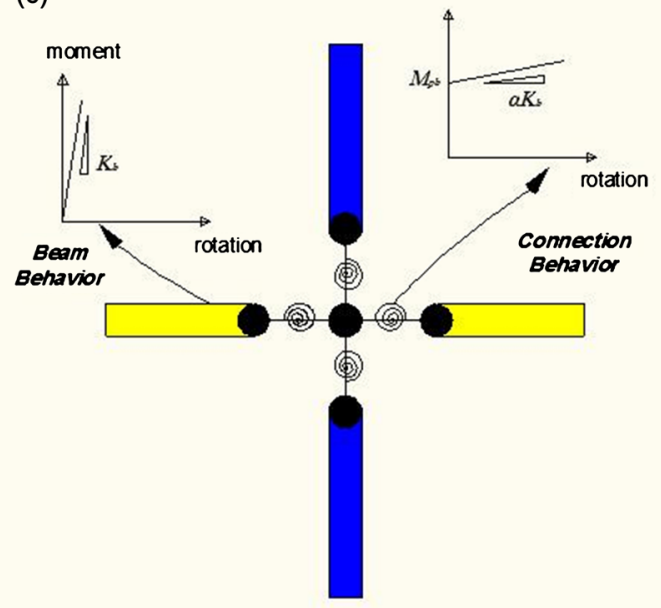

Figure 2. Schematic model of panel-zone elements: (a) Panel-Zone element used in pre-Northridge buildings (corresponding to WUF connection for low ductility buildings); (b) Panel-zone element used in post-Northridge buildings (corresponding to RBS connection for high ductility buildings); (c) Schematic connection modeling in the braced frame. 
joints. Moreover, nodes of beam and column sections are made from joints that do not transfer additional moment resistance to the system.

In order to consider P-delta effects, the weights of internal frame spans (due to the symmetry of half of them) are applied as point loads to the end nodes of rigid beams. When the lateral drift is applied to the buildings, these point loads cause secondary bending moments at the moment-resisting frames. Support columns along with other details are illustrated in Figure 3 based on FEMAP695 [17]. The analytical period of modeled buildings is also shown in Table 2.

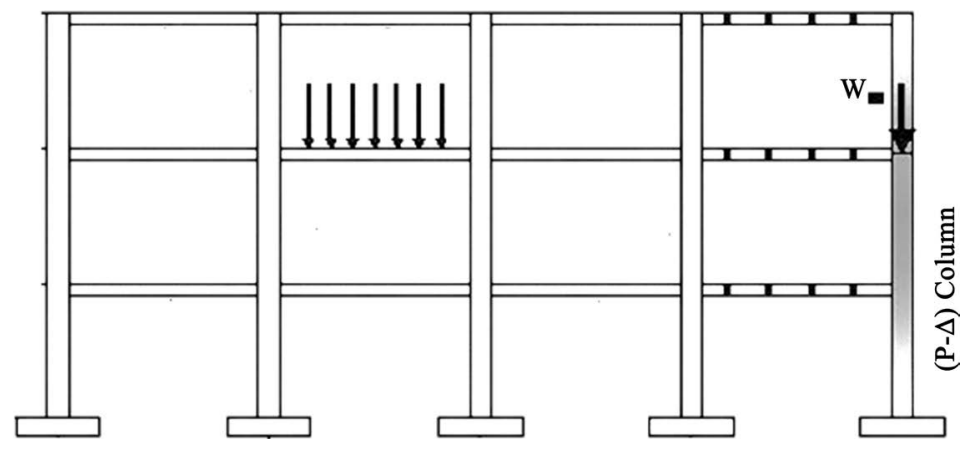

Figure 3. Schematic view of support columns modeling in special moment frames.

Table 2. Obtained periods of buildings.

\begin{tabular}{lccc}
\hline & $\begin{array}{c}\text { Special moment frame } \\
\text { with high ductility }\end{array}$ & $\begin{array}{c}\text { Special moment frame } \\
\text { with low ductility }\end{array}$ & Braced frame \\
\hline T1 according to model & 1.0049 & 0.7501 & 0.35 \\
T1 according to code & $0.0853 \mathrm{H}^{\wedge}(3 / 4)=0.577$ & $0.0853 \mathrm{H}^{\wedge}(3 / 4)=0.577$ & $0.0488 \mathrm{H}^{\wedge}(3 / 4)=0.33$ \\
\hline
\end{tabular}

\section{Record Selection}

The first step in performance assessment method is drawing IDA curves and preparing a series of earthquake ground motions so that it would express regional seismicity [18]. Usually, due to the lack of a sufficient number of recorded earthquakes in the developing countries under consideration, records from other regions are adopted that may not belong to the same seismic plateau, but are similar in terms of earthquake magnitude, source-to-site distance and local geological and subsoil conditions [19]. Here, a limited number of ground motions with similar conditions in terms of seismic characteristics have been used. Thus, sufficient numbers of ground motions, i.e., 22 records in accordance with FEMA P695 recommendations regarding earthquake event and recording station data for the far-field record set, have been used [17]. Magnitude versus distance of selected ground motions diagram has been shown in Figure 4. Also, we can see mean spectra from selected ground motions in Figure 5.

\section{Incremental Dynamic Analysis (IDA)}

The response of the structure under the ground movements can be estimated by time history dynamic analysis. The sensitivity of responses to the selected 


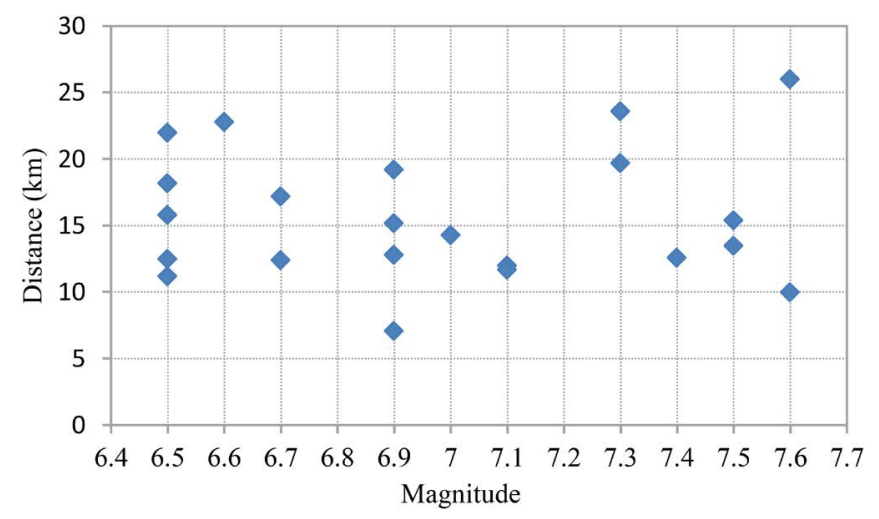

Figure 4. Magnitude versus distance of selected ground motions.

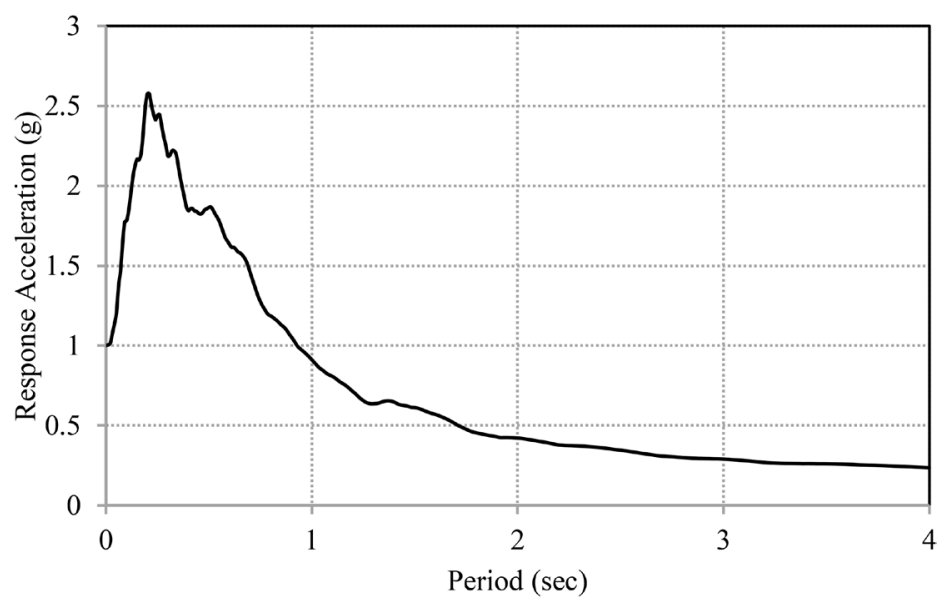

Figure 5. Mean spectra from selected ground motions.

records is one of the most important problems in applying non-linear dynamic analysis [20]. Representing incremental dynamic analysis and estimating responses based on the probability relations can largely decrease this defect. The method of producing IDA curves is exposing one structural modeling subjected to different levels of seismic intensity of one or more earthquake ground motions. Each accelerometer has been measured to reach a special intensity which not only investigates the seismic behavior of buildings but also gives some information to engineers about structural capacities and estimates the seismic performance of buildings [21]. These methods give some information to engineers about structural behaviors, capacity, and seismic performance of buildings by considering structure response to probable intensities of earthquake and structure behavior to strong and rare earthquakes and natural response of the structure to the gradual increase of earthquake intensity and also by estimating dynamic capacity of structural system. The regular form of non-linear incremental dynamic analysis was conducted first to investigate the performance of buildings. Incremental dynamic analysis is performed differently as a parametric analysis to appropriately assess structure performance due to seismic loads [22]. The gradual increase of seismic loads was performed for the first time to investigate structure performance [23] [24]. However, it was regulated for the first 
time to investigate structure performance [21]. PEER has done extensive research on risk analysis and has a close relation with ground science and geological engineering to improve the accuracy of common IMs. Moreover, Cornell investigated different options to seismic intensity values which had the best relation with loss from earthquake [21]. Studies by Shome [25] showed that spectral acceleration for the first mode of the structure and damping of 5\%, Sa (T1,5\%), was considered as appropriate selection for intensity measures (IM). Since this paper focuses on general behavior of the buildings and structural elements, the maximum value of relative story drifts is selected as damage measures (DM) [10]. In the following figures, EDP presents a maximum inter-story drift ratio (max.IDR). It is necessary to use the respective data collected from the records from specified zone to investigate non-linear dynamic analysis of buildings in each site. But these ground motions with wide ranges are not accessible. In this paper, incremental dynamic analysis is used for obtaining IDA curves, in which it is possible to obtain required ground motions by scaling them for analyzing. Obtained curves from this method are shown for three frames in Figure 6 and comparing their percentiles of $50 \%$ have been illustrated in Figure 7. As it can be seen, the mean IDA curve of frame with low ductility will become horizontal in high seismic intensity measure level.

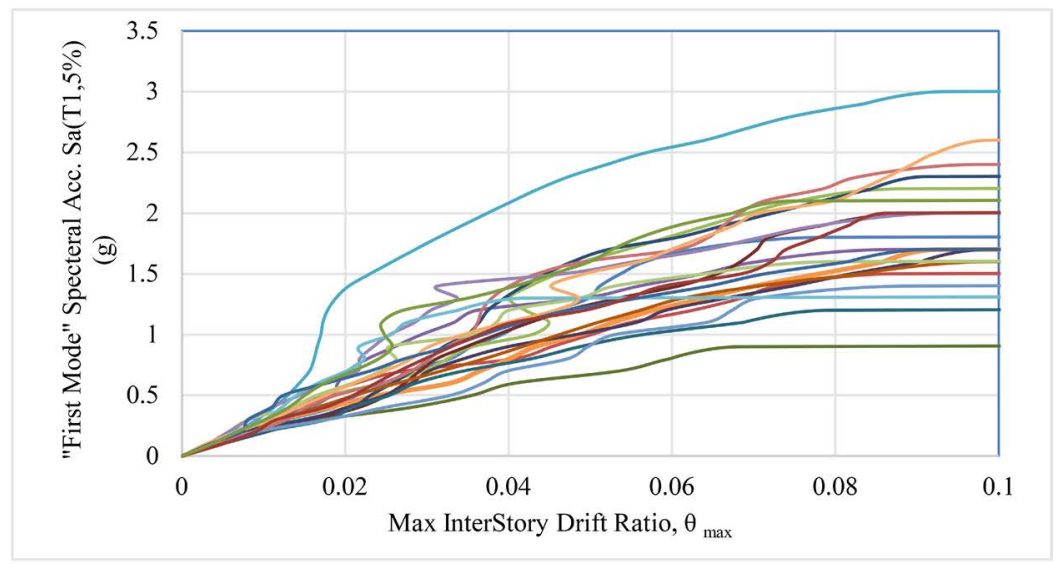

(a)

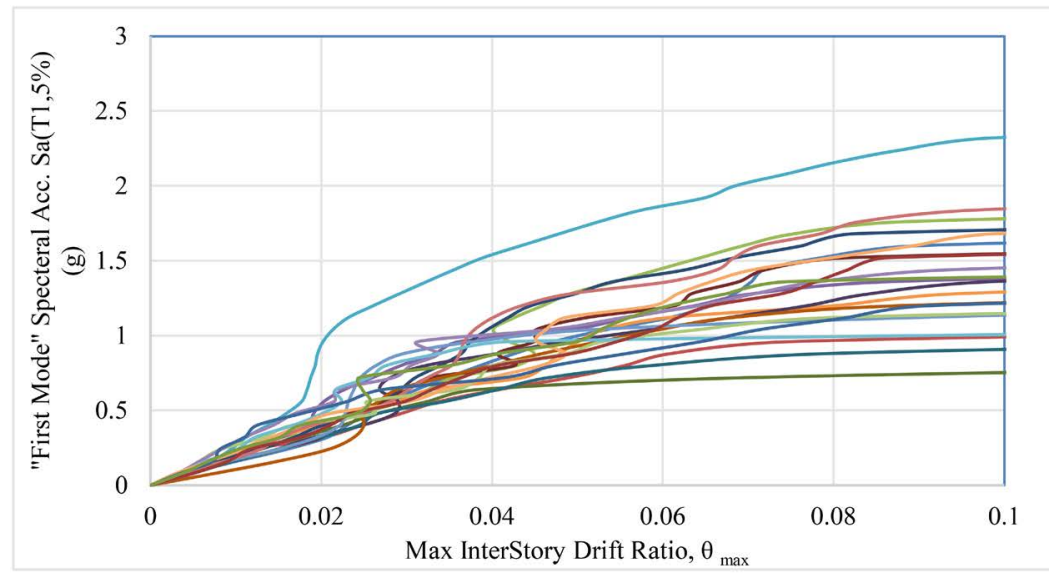

(b) 


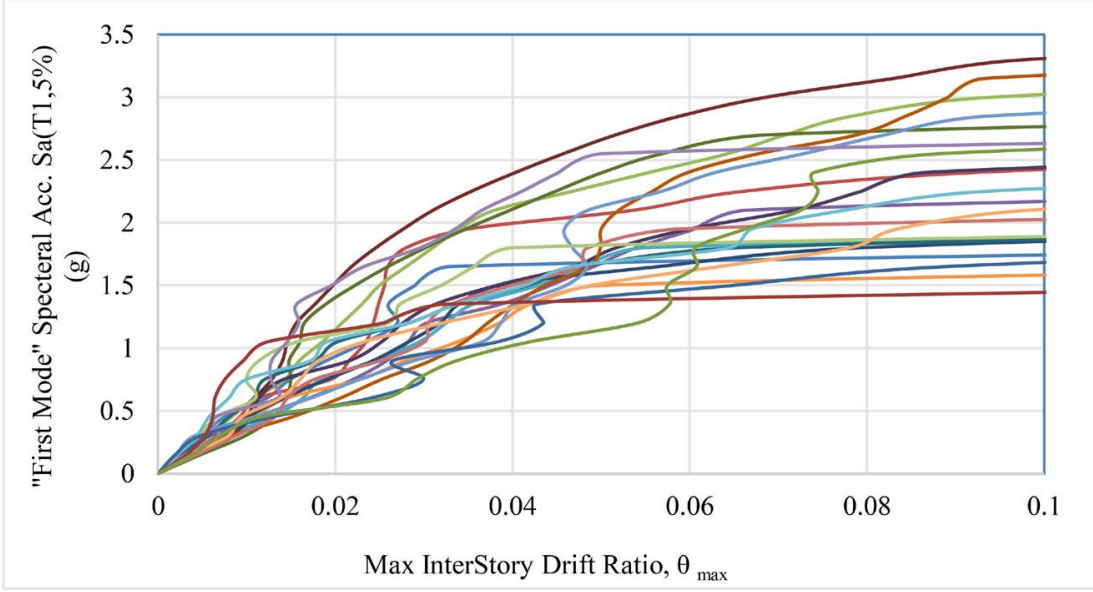

(c)

Figure 6. Obtained IDA curves for special moment frames: (a) For low ductility frame, (b) For high ductility frame, (c) For braced frame.

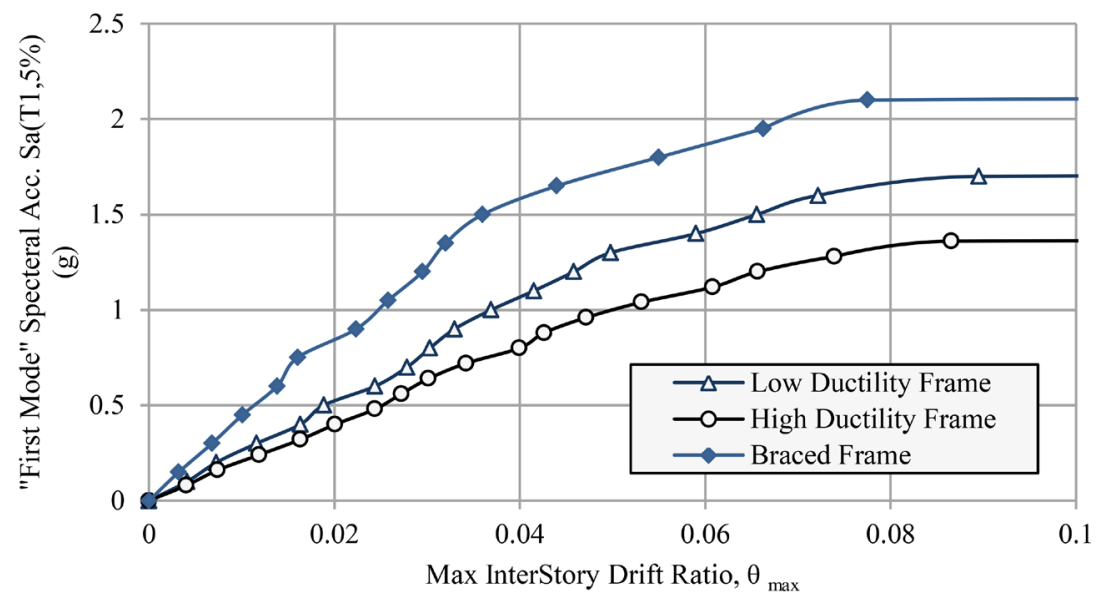

Figure 7. Median IDA curves for three frames.

\section{Fragility Curves}

Fragility curves are used to express structural and non-structural system vulnerabilities as well as performance parameters in buildings [7]. Due to the approach toward earthquake engineering based on performance and due to the importance and necessity of appropriate management of probable crisis such as earthquake, it is necessary to assess vulnerability of structural and non-structural systems. Moreover, an appropriate assessment of probable loss and reasonable decision making becomes more important and necessary. In seismic performancebased design methodology, failure or damage does not happen when the structure is unable to reach defined level of performance requirements [1] [2] and [26]. Fragility curves of collapse level are the most important tools used in the analysis of damage and direct and indirect economic loss effects of earthquakes on buildings. It is possible to observe some obtained fragility curves for structural and nonstructural elements [27] [28] and [29]. Performance requirements are dependent on two connected relations. One of them is related to the relation of seismic in- 
tensity of ground movement and destruction probability (destruction fragility curve). The other one is related to the relation between earthquake risk and earthquake intensity of similar ground movement (earthquake risk curve) [20]. In this article, intensity movement is directly used as destruction probability approach based on seismic intensity (IM-based) [30]. Methods to assess performance values of destruction have been brought in SAC/FEMA guidelines [31] [32]. Therefore, the fragility curves of a structure are considered as fundamental elements to assess destruction performance, known as destruction probability of a structure for seismic intensity of ground movement. For this case, the limited probability of downtime is calculated according to Equation (3):

$$
P\left(C \mid I M=i m_{i}\right)=P\left(i m_{i} \succ I M_{c}\right)=1-F_{I M_{C}}\left(i m_{i}\right)
$$

In Equation (3), $F_{I M_{C}}\left(i m_{i}\right)$ is the cumulative function of capacity probability of seismic intensity. If all input parameters and earthquake effects on buildings are certain, the probable function will be one or zero, but in fact, there are some effects that have inherent nature or cause some changes in the capacity parameter of the structure due to the lack of knowledge. Mathematical view is observable in Equation (4) in which $I M_{C}$ is the defined limited critical case for seismic intensity and $P\left[C \mid I M=i m_{i}\right]$ is the cumulative probability of structural failure for seismic intensity of $\mathrm{im}_{i}$ IMC is corresponding to IM of unstable dynamic mode.

$$
P(A)=P\left[C \mid I M=i m_{i}\right]=P\left[I M_{C} \prec I M=i m_{i}\right]
$$

By using obtained curves, it is possible to calculate the probability of limited case in lieu of each level of IM-provided that IM value is limited to the given level. Using lognormal distribution for points in each IM level, $16^{\text {th }}, 50^{\text {th }}$, and $84^{\text {th }}$ percentiles of IDA curves may be extracted for two damage levels of immediate occupancy (IO) level ( $1 \%$ drift) and collapse prevention (CP) level (10\% drift exceeding) [26]. It should be mentioned that, according to FEMA 350 [33]. Obtained Fragility curves for three models and two limit state levels are shown in Figure 8. From this figure, it can be obtained that there is higher damage probability in each seismic intensity measure for frame with high ductility.

\section{Hazard Curves}

In this section, introduced Seismic hazard Curves derived from Mahdavi et al. research [34]. According to available attenuation relationships, different hazard curves for the seismic zones have been expressed. These curves representing Mean Annual Frequency (MAF) of exceedance from different values of seismic intensity, are obtained for numerous structural periods using the uniform risk map [35]. MAF of exceedance from seismic intensity based on $S_{a}$ is estimated through a linear relation in Log-Log space. The relation related to this estimation is expressed as Equation (5).

$$
\lambda_{S_{a}}=k\left(s_{a}\right)^{t}
$$


$k$ and $t$ parameters, derived from studies about oscillation periods related to the buildings in this article for the area with high level of risk, are brought in Table 3 [34]. Obtained uniform risk curves are illustrated in Figure 9 for each of three frames. $T_{1}$ is frame's period in first shape mode which has obtained from software.

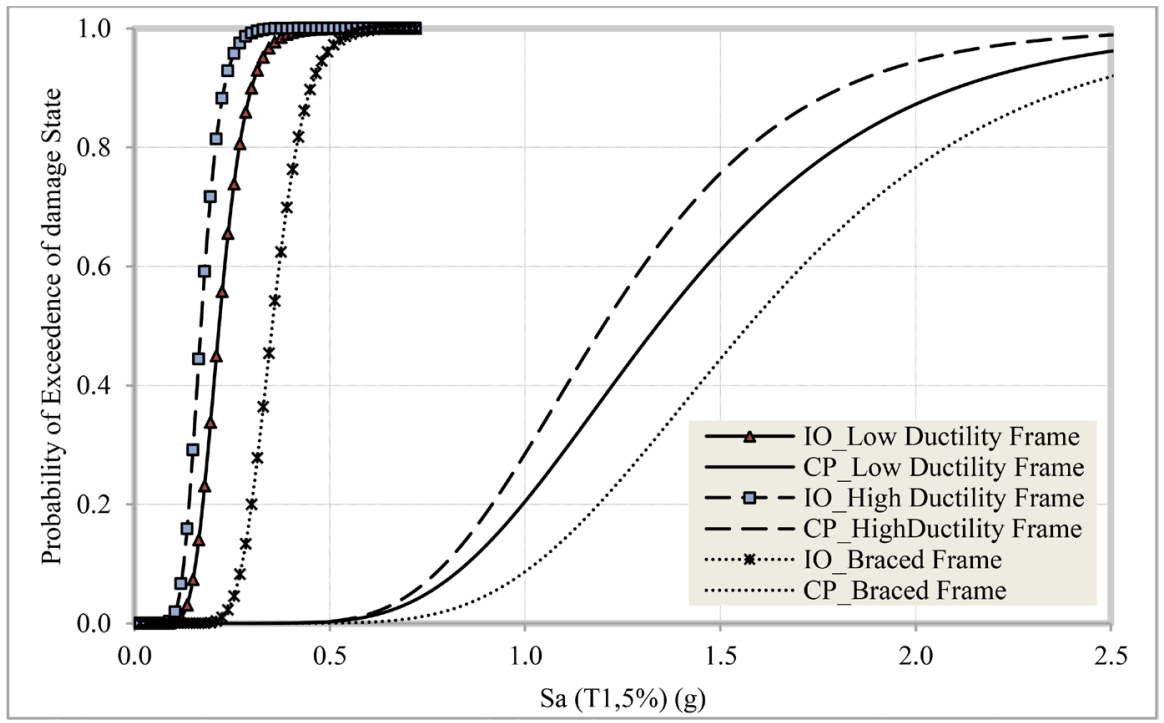

Figure 8. Comparing fragility curves obtained from IM-based method [6] using IDA curves obtained from the common method for two damage levels corresponding to three modeled buildings.

Table 3. Values of $k$ and $t$ parameters corresponding to Equation (5).

\begin{tabular}{cccc}
\hline & \multicolumn{3}{c}{ High Level Hazard } \\
\cline { 2 - 4 } & $T_{1}$ & $\boldsymbol{k}[34]$ & $\boldsymbol{t}[34]$ \\
\hline Special moment frame with high ductility & 1.0049 & $1.42 \mathrm{E}-04$ & -2.011 \\
Special moment frame with low ductility & 0.7501 & $3.72 \mathrm{E}-04$ & -2.068 \\
Braced frame & 0.35 & $1.67 \mathrm{E}-03$ & -2.566 \\
\hline
\end{tabular}

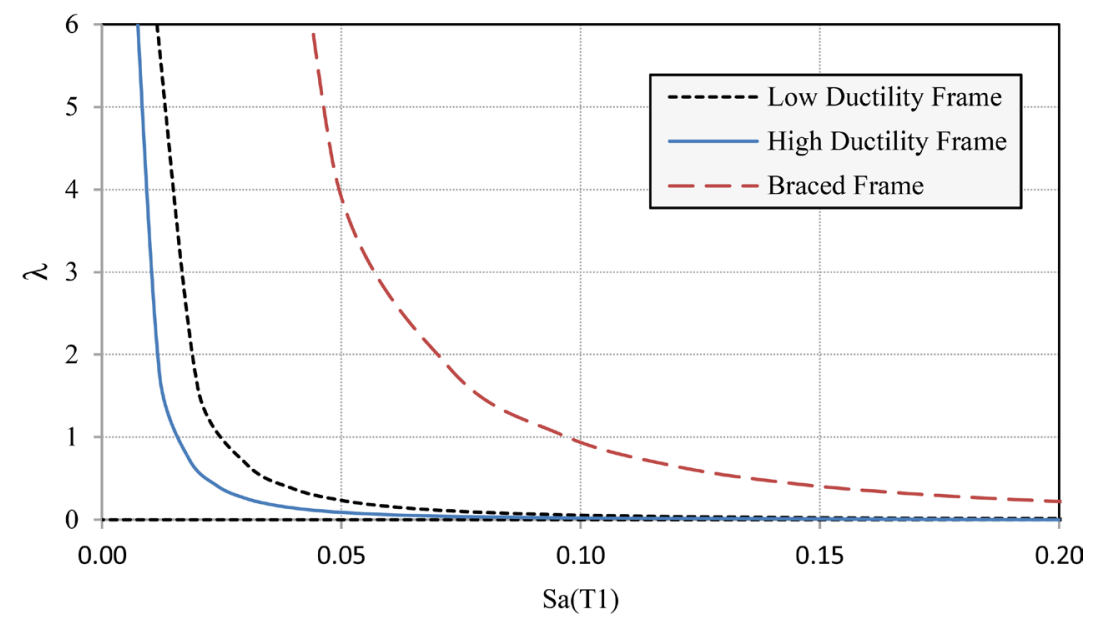

Figure 9. Global comparison between obtained uniform hazard curves in all frames. 


\section{Mean Annual Frequency}

These values are useful as the quantities reflecting the general probabilistic capacity of buildings relying on uncertainties from earthquake. These values can be used as the criteria to measure the structural assurance of available buildings in comparison with other buildings or they can be applied in statutory criteria related to structure designs [1]. Equation (6) is used to calculate mean annual frequency.

$$
\lambda(\text { Collapse })=\int_{0}^{\infty} P\left[\text { Collapse } \mid I M=i m_{i}\right]\left|\frac{\mathrm{d} \lambda\left(I M \succ i m_{i}\right)}{\operatorname{dim}}\right| d(i m)
$$

In Equation (6), $\lambda$ (collapse) represents Mean Annual Frequency (MAF) of exceedance for IM in which the quantity in absolute value, hazard gradient of IM, and $P\left[\right.$ Collapse $\left.\mid I M=i m_{i}\right]$ are damage probability or fragility function value which is obtained using high seismic risk curves (because of building's site location) and fragility curves and numerical integration of Equation (6). Values related to MAF of limit-state levels (IO and CP level) for buildings are illustrated in Table 4. These values are useful as the quantities reflecting the general probabilistic capacity of buildings relying on uncertainties from earthquake. These values can be used as the criteria to measure the structural assurance of available buildings in comparison with other buildings or they can be applied in statutory criteria related to structure designs [27]. It can be seen in Table 4 that the MAF values are higher in low-ductility frames than high-ductility ones, for all two performance levels.

Table 4. Obtained MAF for three buildings.

\begin{tabular}{ccc}
\hline & CP-LEVEL & IO-LEVEL \\
\hline Special moment frame with high ductility & $1.17 \times 10^{-5}$ & $2.43 \times 10^{-5}$ \\
Braced frame & $1.11 \times 10^{-4}$ & $3.6 \times 10^{-4}$ \\
Special moment frame with low ductility & $7.49 \times 10^{-5}$ & $6.1 \times 10^{-5}$ \\
\hline
\end{tabular}

\section{Loss Evaluation}

In order to assess the loss, it is necessary to have functional groups, their positions and their values in the structure. Modeled buildings are assessed for this purpose. The ground story is considered as a parking, and higher stories are categorized as residential building. In each story, there are two units. The least considered performance groups for one story of such buildings have been supposed based on FEMA P-58 instruction and condition of the region [1] [36]. Then, final loss for three buildings is calculated using PACT software. In the software, incremental dynamic analysis results (IDA curves), fragility analysis results (fragility curves) and hazard analysis results (hazard curves) and total cost of building construction per square meters, have been used as the inputs. To implement PACT software, it is necessary to define cost function. These functions are related to contractor attitudes, approaches and procedures in the region. In- 
cremental dynamic analysis results and PACT software are used to calculate non-downtime mode. In order to obtain results for downtime mode (in which major loss for residential buildings occur), cumulative density function, with average cost equal to three times of probable cost repair from structure damage has been supposed with $5 \%$ of distribution. By adding the results for above two modes, loss curves are obtained. Figure 10 and Figure 11 show loss curves and annually probabilistic final loss curves for three case study buildings, respectively.

According to Figure 10 and Figure 11, the braced structure has less annual losses in comparison with other investigated cases, and the structure with high ductility can be considered as the next ones. Performing cost of each building should be considered by contractors. Obviously, the cost of execution of structure with high ductility is more than other buildings. Using the results of this paper can be a common language for decision-making and transfer of information between engineers and employers.

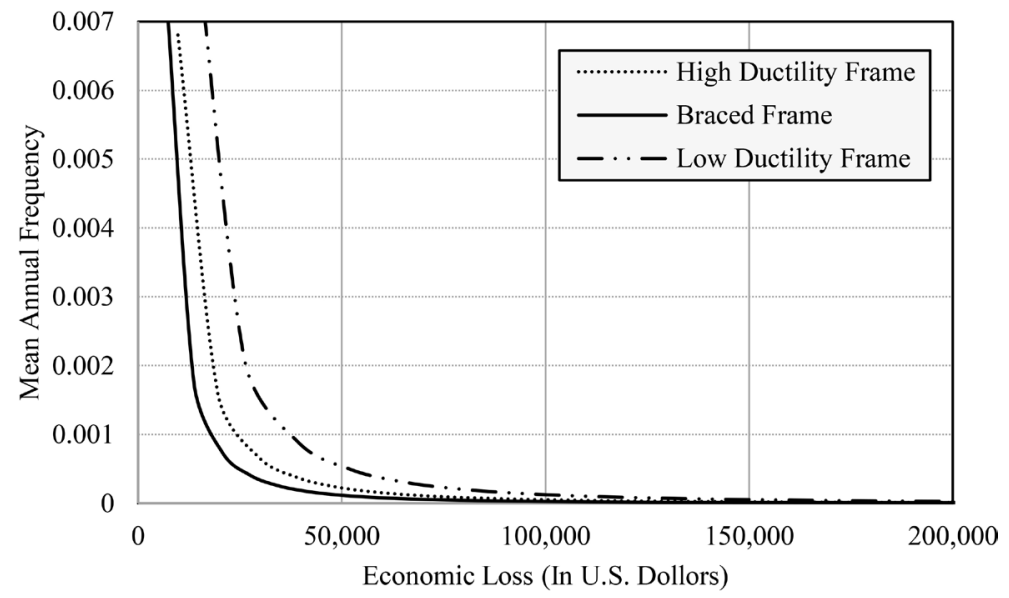

Figure 10. Comparing loss curves obtained from three structure.

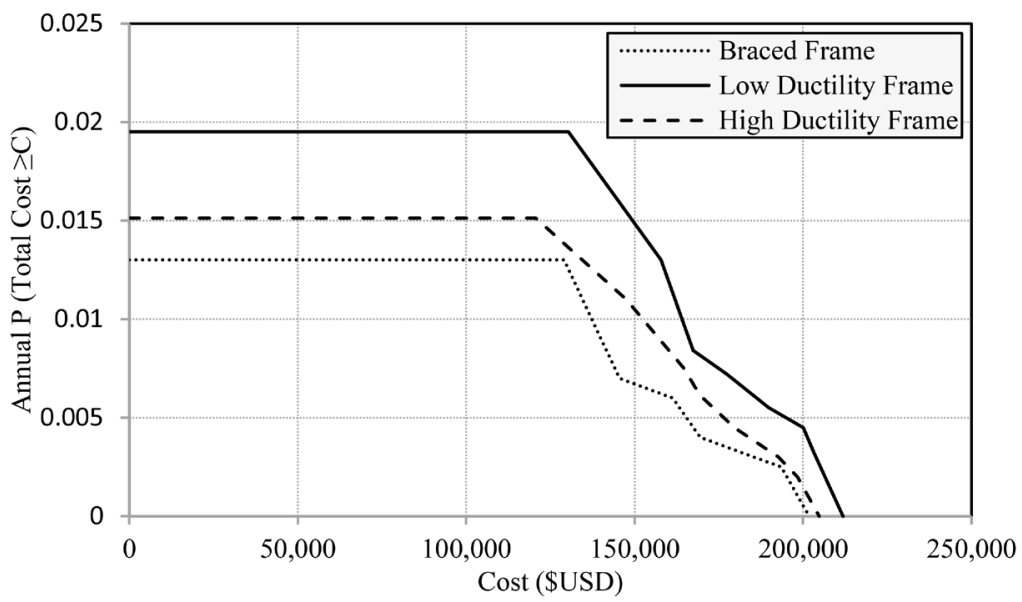

Figure 11. Comparing annually probabilistic final loss curves.

\section{Conclusion}

The present study makes information about economic feasibility for seismic re- 
trofit of existing buildings. In the performance-based design method, it is possible to estimate the behavior of buildings in the case of earthquake. The most important reason of discussion about seismic design based on performance may be encouraging to use innovation in developing some methods to promote performance. In this article, the general method introduced in FEMA P-58 project has been investigated on three buildings. This method helps engineers make rational decisions regarding the selection of global structural components including selection of lateral-resisting systems and optimum use of materials to achieve the desired performance objectives. Implementing this method in developing countries is probabilistic due to some defects in applying this method in terms of tools and necessary data to develop; moreover, this article shows the application of this method through performance assessment. By applying the introduced method in FEMA P-58 project, it is possible to easily obtain loss curves which lead to better communication and making decision between employers and engineers. Estimating annual loss is considered as a valuable tool to assess insurance value for the buildings. Also, it is possible to say that for the investigated structure, braced structure has less annual loss and the structure with high ductility can be considered as the next option. Costs of performing each of the buildings should be considered by contractors, as the cost of execution a structure with high ductility is more than other buildings; moreover, contractors should regard the ease of windward implementation, its speed and architecture. Thus, there is a better communication between contractors and engineers in comparison with the past which leads to making a better decision about designing a structure.

\section{Conflicts of Interest}

The authors declare no conflicts of interest regarding the publication of this paper.

\section{References}

[1] Federal Emergency Management Agency (FEMA) (2012) Seismic Performance Assessment of Buildings, Volume 1, Methodology. Report No. FEMA P-58-1, Washington DC.

[2] Jalayer, F. (2003) Direct Probabilistic Seismic Analysis: Implementation Non-Linear Dynamic Assessments. A Dissertation Submitted to the Department of Civil and Environmental Engineering and the Committee on Graduate Studies of Stanford University in Partial Fulfillment of the Requirements for the Degree of Doctor of Philosophy.

[3] CEN (Comité European de Normalization) (2005) Euro code 8, design of structures for earthquake resistance-Part 2: Bridges. CEN, Brussels.

[4] JGS (2006) Principles for Foundation Designs Grounded on a Performance Based Design Concept (English Version) (JGS4001-2004).

[5] Standards Australia/Standards New Zealand (2002) Structural Design Actions Parts 0 to 3, AS/NZS 1170. Standards Australia/Standards New Zealand, Wellington.

[6] Marijana, H.-N. and Tanja, K.S. (2017) Insights from Existing Earthquake Loss Assessment Research in Croatia. Earthquakes and Structures, 13, 365-375. 
[7] Donatello, C. and Giuseppe, P. (2015) Developing Fragility Curves and Loss Functions for Masonry Infill Walls. Earthquakes and Structures, 9, 257-279. https://doi.org/10.12989/eas.2015.9.1.257

[8] Tafakori, E., Pourzeynali, S. and Estekanchi, H.E. (2017) Probabilistic Seismic Loss Estimation via Endurance Time Method. Earthquake Engineering \& Engineering Vibration, 16, 233-245. https://doi.org/10.1007/s11803-017-0379-8

[9] Li, S., et al. (2017) Performance-Based Seismic Design of Eccentrically Braced Steel Frames Using Target Drift and Failure Mode. Earthquakes and Structures, 13, 443-454.

[10] Beheshti Aval, S.B., Kouhestani, H. and Mottaghi, L. (2017) Effectiveness of Two Conventional Methods for Seismic Retrofit of Steel and RC Moment Resisting Frames Based on Damage Control Criteria. Earthquake Engineering \& Engineering Vibration, 16, 537-555. https://doi.org/10.1007/s11803-017-0404-y

[11] Uniform Building Code (UBC) (1997) Structural Engineering Design Provisions Vol. 2.

[12] ANSI/AISC 360-10 (2010) Specification for Structural Steel Buildings. American Institute of Steel Construction, Chicago.

[13] Ashkezari, Gh.D. (2018) A Performance Based Strategy for Design of Steel Moment Frames under Blast Loading. Earthquakes and Structures, 15, 155-164.

[14] Beheshti Aval, S.B. and Masoumi Verki, A. (2019) Seismic Reliability Assessment of a Steel Moment-Resisting Frame with Two Different Ductility Levels Using a Cloud Analysis Approach. Earthquake Engineering \& Engineering Vibration, 18, 171-185. https://doi.org/10.1007/s11803-019-0497-6

[15] Lignos, D. and Krawinkler, H. (2007) A Database in Support of Modeling of Component Deterioration for Collapse Prediction of Steel Frame Structures. Research Frontiers at Structures Congress, Long Beach, 16-19 May 2007, 16-19. https://doi.org/10.1061/40944(249)31

[16] Masoumi Verki, A. (2012) Performance-Base Design through Implementation of ATC-58 Guideline on a Conventional Structure (Flexural-Bracy Frame) in Iran. Thesis Submitted for the Degree of Master of Seismic Engineering, K. N. Toosi University of Technology (KNTU), Department of Civil Engineering, Tehran.

[17] Federal Emergency Management Agency (FEMA) (2009) Quantification of Building Seismic Performance Factors. Report No. FEMA-P695, Prepared by the Building Seismic Safety Council for the Federal Emergency Management Agency, Washington DC.

[18] Khorami, M., Alvansazyazdi, M., Shariati, M., Zandi, Y., Jalali, A. and Tahir, M. (2017) Seismic Performance Evaluation of Buckling Restrained Braced Frames (BRBF) Using Incremental Nonlinear Dynamic Analysis Method (IDA). Earthquakes and Structures, 13, 531-538.

[19] Li, B., Xie, W. and Pandey, M.D. (2016) Newmark Design Spectra Considering Earthquake Magnitudes and Site Categories. Earthquake Engineering \& Engineering Vibration, 15, 519-535. https://doi.org/10.1007/s11803-016-0341-1

[20] Liang, F., et al. (2017) Accuracy of Three-Dimensional Seismic Ground Response Analysis in Time Domain Using Nonlinear Numerical Simulations. Earthquake Engineering \& Engineering Vibration, 16, 487-498. https://doi.org/10.1007/s11803-017-0401-1

[21] Vamvatsikos, D. and Cornell, C.A. (2002) Incremental Dynamic Analysis. Journal of Earthquake Engineering and Structural Dynamics, 31, 491-514. https://doi.org/10.1002/eqe.141 
[22] Bahramirad, A., Tehranizadeh, M. and Moshref, A. (2015) Equating Incremental Dynamic Analysis with Static Nonlinear Analysis at Near-Field Excitation. Earthquake Engineering \& Engineering Vibration, 14, 465-476. https://doi.org/10.1007/s11803-015-0037-y

[23] Bertero, V. (1977) Strength and Deformation Capacities of Buildings under Extreme Environments. Structural Engineering and Structural Mechanics, 53, 29-79.

[24] Mehanny, F. and Deierlein, G. (2000) Modeling of Assessment of Seismic Performance of Composite Frames with Reinforced Concrete Columns and Steel Beams. John A. Blume Earthquake Engineering Research Center, Department of Civil Engineering, Stanford University, Stanford.

[25] Shome, N. and Cornell, C.A. (1999) Probabilistic Seismic Demand Analysis of Nonlinear Structures. Reliability of Marine Structures, Program Report No. RMS-35, Department of Civil and Environmental Engineering, Stanford University, Stanford.

[26] Zareian, F., Lignos, D., Krawinkler, H. and Ibarra, L. (2010) Basic Concept and Performance Measures in Prediction of Collapse of Buildings under Earthquake Ground Motions. The Structural Design of Tall and Special Buildings, 19, 167-181. https://doi.org/10.1002/tal.546

[27] Aslani, H. and Miranda, E. (2005) Fragility Assessment of Slab-Column Connections in Existing Non-Ductile Reinforced Concrete Buildings. Journal of Earthquake Engineering, 9, 777-804. https://doi.org/10.1080/13632460509350566

[28] Eberhard, M., Mookerjee, A. and Parrish, M. (2001) Uncertainties in Performance Estimates for RC Columns. PEER Center, Richmond.

[29] Hutchinson, T. and Chaudhuri, R. (2004) Seismic Fragility of Small Equipment and Contents. PBSD Concepts and Impl. PEER Report 2004/\#. (In Press) http://peer.berkeley.edu

[30] Beheshti, A., Masoumi Verki, A., Rastegaran, M., et al. (2014) Systematical Approach to Evaluate Collapse Probability of Steel MRF Buildings Based on Engineering Demand and Intensity Measure. International Journal of Structural Analysis \& Design, 1, 14-18.

[31] Federal Emergency Management Agency (FEMA) (2000) State of the Art Report on Performance Prediction and Evaluation of Steel Moment-Frame Buildings. Report No. FEMA-355F, Federal Emergency Management Agency, Washington DC.

[32] Ibarra, L.F. and Krawinkler, H. (2005) Global Collapse of Frame Buildings under Seismic Excitations. Report No. PEER2005/06, Pacific Earthquake Engineering Research Center, University of California at Berkeley, Berkeley.

[33] Federal Emergency Management Agency (FEMA) (2000) Recommended Seismic Design Criteria for New Steel Moment-Frame Buildings. Report No. FEMA 350, Washington DC.

[34] Mahdavi, A., Banazadeh, M. and Deylami, A. (2011) Bayesian Approach for Determination of Drift Hazard Curves for Generic Steel Moment-Resisting Frames in Territory of Tehran. International Journal of Civil Engineering \& Structural Engineering, 9, 145-154.

[35] Mahdavi, A., Banazadeh, M. and Deylami, A. (2010) Determination of Drift Hazard Curves of Steel Moment-Resisting Frames for Territory of Tehran City. 9 th US National and 10th Canadian Conference on Earthquake Engineering, Toronto, 25-29 July 2010, 25-29.

[36] Krawinkler, H. (2004) Exercising Seismic Performance Assessment. Van Nuys Hotel Building Testbed Report, PEER Report. 